\title{
PRODUÇÃO DE SERAPILHEIRA EM DOIS ESTÁDIOS SUCESSIONAIS DE FLORESTA ESTACIONAL SEMIDECIDUAL NA RESERVA MATA DO PARAÍSO, EM VIÇOSA, MG ${ }^{1}$
}

\author{
Sheila Isabel do Carmo Pinto², Sebastião Venâncio Martins³, Nairam Félix de Barros ${ }^{4}$, Herly Carlos \\ Teixeira Dias ${ }^{3}$
}

\begin{abstract}
RESUMO - Dois trechos de floresta em distintos estádios sucessionais (floresta inicial e floresta madura) foram avaliados quanto à produção de serapilheira durante o período compreendido entre novembro/ 2003 e outubro/2004. Os objetivos foram estimar a produção anual de serapilheira, verificar a variação temporal de deposição da serapilheira e investigar a existência de correlações entre a estrutura da vegetação e a produção de serapilheira. O estudo foi realizado na Reserva Mata do Paraíso, em Viçosa, MG, onde foram instalados 20 coletores de $1 \mathrm{~m}^{2}$, colocados a $20 \mathrm{~cm}$ acima da superfície do solo. Os coletores foram distribuídos no centro de parcelas de formato retangular, medindo 10 x $30 \mathrm{~m}$ cada um, e cada trecho de floresta recebeu 10 coletores. A serapilheira coletada mensalmente foi separada nas frações folhas, ramos, flores e frutos/sementes. A produção anual de serapilheira foi estimada em $6.310 \mathrm{~kg}$.ha- $\mathrm{a}^{-1}$ na floresta inicial e $8.819 \mathrm{~kg} \cdot \mathrm{ha}^{-1}$ na floresta madura. A fração predominante foi a foliar $(64,6 \%$ e $55,9 \%)$, seguida das frações ramos $(31,2 \%$ e $36,4 \%)$, frutos e sementes $(3,2 \%$ e $6,2 \%)$ e flores $(1,0 \%$ e $1,5 \%)$, nas florestas inicial e madura, respectivamente. A produção de serapilheira total foi contínua ao longo do período analisado, apresentando modelo sazonal, com os maiores valores no período da primavera. Na fração foliar, o pico de produção foi verificado em setembro, no final da estação seca. A produção de serapilheira esteve mais relacionada à densidade de indivíduos nas parcelas e à sua biomassa do que à presença de espécies pioneiras nos ambientes estudados.
\end{abstract}

Palavras-chave: Serapilheira, deposição de serapilheira, floresta estacional semidecidual e estádios sucessionais.

\section{LITTER PRODUCTION IN TWO SUCCESSIONAL STAGES OF A TROPICAL SEMIDECIDUOUS FOREST IN THE MATA DO PARAÍSO FOREST RESERVE IN VIÇOSA, MG}

\begin{abstract}
Litter production in two sites of forest (initial forest and mature forest) was evaluated during twelve months, between November/2003 and October/2004, for the estimation of annual litter production, evaluating the time variation of litter deposition and investigating the existence of correlations between vegetation structure and litter production. The study was carried out in the Mata do Paraiso Forest Reserve, nearby Viçosa, MG. Twenty $1 \mathrm{~m} 2$ litter traps were placed $20 \mathrm{~cm}$ above the soil surface. The litter traps were distributed in the center of the $10 \times 30 \mathrm{~m}$ plots, ten litter traps in each forest site. Sampling was carried out on monthly basis. The material deposited in the traps was separated into leaves, branches, flowers and seeds. The annual litter production was estimated at $6,310 \mathrm{~kg} . \mathrm{ha}^{-1}$ for the young forest and $8,819 \mathrm{~kg} . \mathrm{ha}^{-1}$ for the mature forest. Leaves were the predominant fraction (64.6\% and $55.9 \%)$, followed by branches $(31.2 \%$ and $36.4 \%)$, fruits and seeds $(3.2 \%$ and $6.2 \%)$ and flowers $(1.0 \%$ and $1.5 \%)$ for the young forest and mature forest, respectively.
\end{abstract}

\footnotetext{
${ }^{1}$ Recebido em 30.04.2007 e aceito para publicação em 19.05.2008.

${ }^{2}$ Programa de Pós-Graduação em Ciência Florestal da Universidade Federal de Viçosa (UFV), Viçosa-MG. E-mail:<sheilaicp@yahoo.com.br>.

${ }^{3}$ Departamento de Engenharia Florestal da UFV. E-mail: <venancio@ufv.br>.

${ }^{4}$ Departamento de Solos da UFV. E-mail: <nfbarros@ufv.br>.
} 
Litter production was uniform throughout the period analyzed showing a seasonal pattern with the largest values in the spring. Maximum production for the leaf fraction was found in September, at the end of the dry season. Litter production was more correlated with density of individuals in the plots and biomass than with pioneer species dominance.

Keywords:Litter, litterfall, tropical semideciduous forest and successional stages.

\section{INTRODUÇÃO}

A serapilheira é um componente de suma importância em um ecossistema florestal, pois responde pela ciclagem de nutrientes, além de indicar a capacidade produtiva da floresta ao relacionar os nutrientes disponíveis com as necessidades nutricionais de dada espécie arbórea (FIGUEIREDOFILHO etal., 2003). Auxilia a compreensão dos aspectos dinâmicos das populações e atua indiretamente na estrutura da comunidade (FACELLI e PICKETT, 1991). Sua produção e decomposição são utilizadas como indicadores de restauração em projetos de recuperação de áreas degradadas (ARATO et al., 2003).

Os padrões de deposição da serapilheira produzem heterogeneidade temporal e espacial no ambiente florestal, podendo afetar a estrutura e dinâmica da comunidade de plantas (FACELLI e PICKETT, 1991; MOLOFSKY e AUGSPURGER, 1992), constituindo um aspecto relevante para o conhecimento e preservação dos ecossistemas naturais.

Vários fatores bióticos e abióticos afetam a produção de serapilheira, como tipo de vegetação, altitude, latitude, precipitação, temperatura, regimes de luminosidade, deciduidade da vegetação, estádio sucessional, disponibilidade hídrica e características do solo. A estrutura vertical e horizontal da comunidade vegetal e a composição e distribuição de espécies também podem interferir na distribuição e produção de serapilheira (LOWMAN, 1988). No entanto, dependendo das características de cada ecossistema, determinado fator pode prevalecer sobre os demais (FIGUEIREDO FILHO et al., 2003).

Os estudos da ciclagem de nutrientes, principalmente via produção de serapilheira, têm sido considerados como um dos assuntos de grande relevância para o entendimento do funcionamento dos ecossistemas florestais (PROCTOR, 1983), podendo facilitar a determinação do grau de fragilidade deles diante da crescente ocupação dos ambientes naturais
(CESAR, 1993). No entanto, poucos estudos têm abordado a produção de serapilheira em áreas submetidas a distúrbios, apesar de ser importante entender a relação desse compartimento com o processo regenerativo da vegetação (MARTINS e RODRIGUES, 1999), principalmente, nos diversos estádios sucessionais dos remanescentes florestais oriundos dos processos de fragmentação.

Nesse contexto, este estudo teve por objetivos quantificar a produção anual de serapilheira em dois trechos de floresta na Reserva Mata do Paraíso em estádios inicial e maduro de sucessão, verificar a variação temporal de deposição da serapilheira nesses ambientes; e investigar a existência de correlações entre as variáveis climáticas e características estruturais da vegetação e a produção de serapilheira.

\section{MATERIAL E MÉTODOS}

O estudo foi conduzido na Reserva Mata do Paraíso, também conhecida como Estação de Pesquisa e Educação Ambiental $\left(20^{\circ} 48^{\prime} 07^{\prime \prime S ~ e ~ 42 ~ 51 ' 31 " W), ~ p e r t e n c e n t e ~ a ̀ ~}\right.$ Universidade Federal de Viçosa, no Município de Viçosa, Zona da Mata de Minas Gerais. A área possui 195 há, e a altitude varia de 690 a 800 m (BRAZ et al., 2002).

O clima na região é do tipo Cwb (Köppen), mesotérmico com verões quentes e chuvosos e invernos frios e secos. A temperatura média anual é de $21,8^{\circ} \mathrm{C}$, a precipitação pluviométrica média anual é de 1.314,2 mm (CASTRO et al., 1983) e a precipitação efetiva registrada no período chuvoso é em torno de $80 \%$ da precipitação total na Reserva Mata do Paraíso (OLIVEIRA JÚNIOR e DIAS, 2005).

A vegetação da reserva é composta por trechos de floresta estacional semidecidual, compondo um mosaico de diferentes estádios sucessionais. Os trechos da reserva escolhidos para este estudo apresentam diferentes históricos de perturbação e regeneração e foram identificados por Silva Júnior et al. (2004). Um desses trechos, denominado neste estudo floresta inicial, 
encontra-se em processo de regeneração florestal a partir de pastagem de Melinis minutiflora P. Beavv. desde 1963, quando a área foi cercada e abandonada. O outro trecho de floresta, denominado floresta madura, constitui um núcleo de floresta bem preservado, livre de distúrbios antrópicos há pelos menos 40 anos (SILVA JÚNIOR et al., 2004).

Para avaliar a produção de serapilheira nas florestas inicial e madura, foram utilizados 10 coletores de $1 \mathrm{~m}^{2}$ ( $1 \times 1 \mathrm{~m})$ com fundo de tela de náilon com malha de $1 \times 1 \mathrm{~mm}$, em cada trecho estudado, totalizando, assim, 20 coletores. Os coletores foram distribuídos no centro de cada parcela, cujo formato era retangular $(10 \times 30$ $\mathrm{m})$, colocados a $20 \mathrm{~cm}$ acima da superfície do solo. $\mathrm{O}$ material interceptado pelos coletores foi recolhido regularmente em intervalos de 30 dias. As coletas foram realizadas durante um período de 12 meses, compreendido entre novembro/2003 e outubro/2004. A serapilheira coletada foi separada manualmente nas frações folhas, flores, frutos/sementes e ramos com até $2 \mathrm{~cm}$ de diâmetro. Depois da triagem, as frações foram secas em estufa a $70{ }^{\circ} \mathrm{C}$ e pesadas.

Com os dados obtidos, calcularam-se as médias mensais de deposição da serapilheira total e de suas frações, expressando os valores em kg.ha-1 e em porcentagem de cada fração. Também, foram feitas comparações entre a produção mensal e a produção total das florestas inicial e madura, por meio do teste de Student, para amostras não pareadas.
Por meio de análise de regressão, investigaramse as relações entre a produção de serapilheira e os parâmetros da estrutura da vegetação arbustivo-arbórea presente nas parcelas (foram medidos todos os indivíduos arbustivo-arbóreos com diâmetro a $1,30 \mathrm{~m}$ do solo (DAP) $\geq 4,8 \mathrm{~cm}$ - dados não publicados): densidade total, área basal, altura média, número de indivíduos amostrados do grupo ecológico das espécies pioneiras nas parcelas e porcentagem de abertura do dossel.

A porcentagem de abertura do dossel foi determinada por meio de fotografias hemisféricas obtidas no centro de cada parcela (localização dos coletores) com a utilização de uma lente de $8 \mathrm{~mm}$, com ângulo de $180^{\circ}$, fixada em uma câmara fotográfica, com filme ASA 400, voltada para o céu. Após a revelação das fotografias, elas foram digitalizadas em scanner e classificadas pelo programa PHOTOSHOP 6.0 e processadas pelo programa HEMIPHOT (STEEGE, 1993), estimando-se, assim, a porcentagem de abertura do dossel em cada parcela.

Para avaliar a influência de fatores climáticos na produção de serapilheira ao longo do período de estudo, foi calculada a matriz de correlação de Pearson entre a produção mensal de serapilheira, produção da fração foliar e as variáveis climáticas. Os dados climáticos foram cedidos pela Estação Meteorológica da Universidade Federal de Viçosa, sob a coordenação do Departamento de Engenharia Agrícola (Quadro 1).

Quadro 1 - Dados climáticos obtidos pela Estação Meteorológica da Universidade Federal de Viçosa, durante o período de estudo (novembro/2003 a outubro/2004)

Table 1 -Climate data obtained of Estação Meteorológica of Universidade Federal de Viçosa during the study period (noveber) 2003 to october /2004)

\begin{tabular}{|c|c|c|c|c|c|c|c|}
\hline Mês & $\begin{array}{c}\operatorname{Tmax}^{1} \\
{ }^{\circ} \mathrm{C} \\
\end{array}$ & $\begin{array}{c}\operatorname{Tmin}^{1} \\
{ }^{\circ} \mathrm{C} \\
\end{array}$ & $\begin{array}{c}\text { Tmed }^{1} \\
{ }^{\circ} \mathrm{C} \\
\end{array}$ & $\begin{array}{l}\mathrm{Ppt}^{1} \\
\mathrm{~mm}\end{array}$ & $\begin{array}{c}\text { Insol }^{1} \\
\mathrm{~h}\end{array}$ & $\begin{array}{c}\mathrm{UR}^{1} \\
\% \\
\end{array}$ & $\begin{array}{l}\text { Vent }{ }^{1} \\
\mathrm{~m}_{\mathrm{s}} \mathrm{s}^{-1}\end{array}$ \\
\hline Novembro & 27,9 & 17,8 & 21,8 & 163,8 & 4,4 & 77 & 1,3 \\
\hline Dezembro & 29,1 & 19,4 & 22,9 & 252,1 & 3,5 & 81 & 1,3 \\
\hline Janeiro & 27,3 & 18,7 & 22,1 & 405,9 & 0 & 82 & 1,3 \\
\hline Fevereiro & 27,5 & 18,7 & 21,9 & 388,4 & 3,3 & 84 & 1,2 \\
\hline Março & 27,9 & 17,7 & 21,0 & 174,4 & 6,1 & 82 & 0,8 \\
\hline Abril & 26,4 & 17,4 & 20,7 & 136,7 & 5,4 & 86 & 0,7 \\
\hline Maio & 23,9 & 14,6 & 18,1 & 41,6 & 4,4 & 87 & 0,7 \\
\hline Junho & 22,8 & 11,8 & 15,8 & 40,7 & 4,9 & 87 & 0,7 \\
\hline Julho & 22,3 & 11,8 & 15,6 & 35,6 & 5,6 & 86 & 0,8 \\
\hline Agosto & 25,2 & 11,5 & 16,9 & 0,2 & 7,3 & 80 & 1,0 \\
\hline Setembro & 28,2 & 13,7 & 19,9 & 0 & 7,4 & 71 & 1,4 \\
\hline Outubro & 26,6 & 16,7 & 20,7 & 66,2 & 4,6 & 80 & 1,1 \\
\hline
\end{tabular}

${ }^{1}$ Tmax (média das temperaturas máximas), Tmin (média das temperaturas mínimas), Tmed (temperatura média mensal), Ppt (precipitação pluviométrica), UR (umidade relativa), Insol (insolação média) e Vent (velocidade do vento). 


\section{RESULTADOS E DISCUSSÃO}

\subsection{Produção e variação temporal de deposição da serapilheira}

A produção anual de serapilheira apresentada pela floresta madura (8.819,7 kg.ha-1) foi significativamente superior à da floresta inicial $\left(6.310,1 \mathrm{~kg} \cdot \mathrm{ha}^{-1}\right)$ (Quadro 2). Os registros das deposições mensais na floresta madura ao longo do ano também se mostraram superiores. As exceções foram os meses de maio e julho, quando a floresta inicial obteve maior aporte de biomassa proveniente, principalmente, da queda de galhos (Figura 1).

A produção anual de serapilheira obtida, considerando-se os dois trechos de floresta deste estudo, encontra-se entre os valores registrados em Florestas Estacionais Semideciduais no Sudeste do Brasil (WERNECK et al., 2001; DIAS e OLIVEIRA FILHO, 1997; CESAR, 1993; MORELLATO, 1992; MARTINS e RODRIGUES, 1999).

Maiores produções de serapilheira em estádios sucessionais mais avançados de florestas tropicais foram também obtidos em estudos realizados em florestas tropicais na região Amazônica (DANTAS e PHILLIPSON, 1989; MARTIUS et al., 2004), no México (SANCHEZ eALVAREZSANCHEZ, 1995), na Jamaica(MCDONALD e HEALY, 2000) e na floresta semidecídua da Estação Ecológica do Tripuí, MG (WERNECK et al., 2001).

A grande abundância de espécies pioneiras foi preponderante para a maior produção de serapilheira em trechos sucessionais iniciais na Floresta Atlântica, em Cubatão, SP (LEITÃO-FILHO et al., 1993), e em clareiras de floresta semidecídua de Campinas, SP,
(MARTINS e RODRIGUES, 1999). Essa tendência não foi constatada neste estudo, uma vez que a floresta inicial, com maiores porcentagens de espécies arbóreas pioneiras, segundo os critérios adotados por Gandolfi et al. (1995), apresentou menor produção de serapilheira total, quando comparada com a floresta madura.

A produção de serapilheira total e das frações frutos/sementes e flores foi significativamente maior na floresta madura. Contudo, as frações folhas e ramos não apresentaram diferenças significativas entre os dois trechos de floresta estudados (Quadro 2). A fração foliar foi predominante nas duas áreas estudadas, apresentando as maiores porcentagens do peso de matéria seca total $(64,6$ e 55,9\%), seguida das frações ramos $(31,2$ e $36,4 \%)$, frutos e sementes $(3,2$ e $6,2 \%)$ e flores $(1,0$ e $1,5 \%)$ nas florestas inicial e madura, respectivamente (Quadro 2). Os maiores valores de produção da serapilheira total e da fração foliar foram alcançados durante a primavera, final da estação seca, nos dois trechos de floresta estudados, sendo responsável por cerca de $45 \%$ da produção total anual de serapilheira na floresta inicial e de $46,8 \%$ na floresta madura.

O padrão de variação temporal da produção de serapilheira total e, principalmente, da fração foliar encontrado neste estudo, com os maiores valores de deposição coincidindo com o final da estação seca, também foi constatado em vários remanescentes de Floresta Estacional Semidecidual do Sudeste Brasileiro (CESAR, 1993; DIASeOLIVEIRAFILHO 1997;MARTINS e RODRIGUES, 1999; MORELLATO, 1992; WERNECK et al., 2001). Isso deve estar relacionado às baixas taxas de precipitação registradas nessa época do ano (MORELLATO, 1992).

Quadro 2 - Estimativa da produção anual de serapilheira nas florestas inicial e madura na Reserva Mata do Paraíso, em Viçosa, MG

Table 2 - Estimative of annual production of litter for initial and mature forests in the Mata do Paraiso Forest Reserve in Viçosa, $M G$

\begin{tabular}{|c|c|c|c|c|c|}
\hline & \multicolumn{2}{|c|}{ Floresta Inicial } & \multicolumn{2}{|c|}{ Floresta Madura } & \multirow[t]{2}{*}{$\mathrm{P}^{1}$} \\
\hline & kg.ha ${ }^{-1} \pm$ desvio & $\%$ & kg.ha' ${ }^{-1} \pm$ desvio & $\%$ & \\
\hline Folhas & $4.079,7 \pm 147,9$ & 64,6 & $4.932,4 \pm 215,4$ & 55,9 & $0,356^{\mathrm{NS}}$ \\
\hline Ramos & $1.970,4 \pm 85,1$ & 31,2 & $3.209,3 \pm 169,7$ & 36,4 & $0,728^{\mathrm{NS}}$ \\
\hline Frutos/sementes & $198,8 \pm 9,8$ & 3,2 & $543,5 \pm 24,9$ & 6,2 & $0,001 * *$ \\
\hline Flores & $61,3 \pm 3,1$ & 1,0 & $134,5 \pm 6,5$ & 1,5 & $0,007 * *$ \\
\hline Total & $6.310,1 \pm 187,3$ & & $8.819,7 \pm 282,0$ & & $0,043^{*}$ \\
\hline
\end{tabular}

${ }^{1}$ As comparações foram efetuadas pelo teste de Student não pareado, em que: (* significância a $5 \%$ de probabilidade; ** significância a $1 \%$ de probabilidade; e Ns ausência de significância).

R. Árvore, Viçosa-MG, v.32, n.3, p.545-556, 2008 


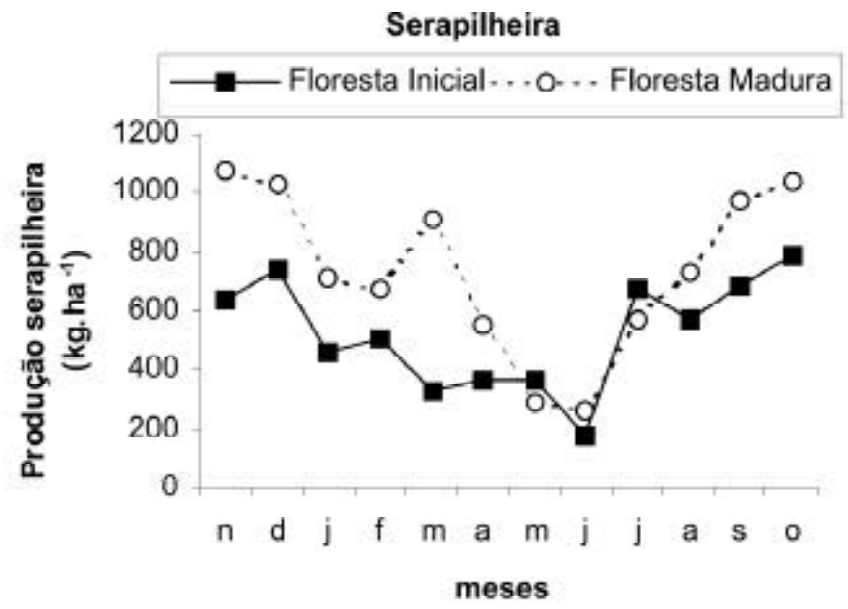

\section{Fração Folhas}

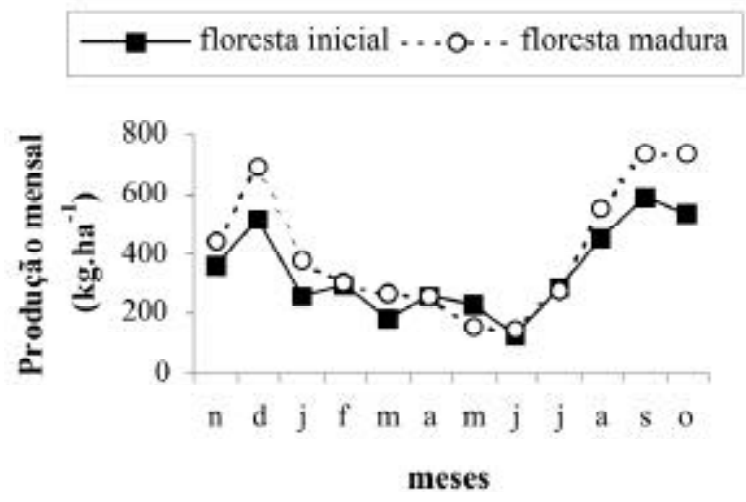

Fraçāo Frutos

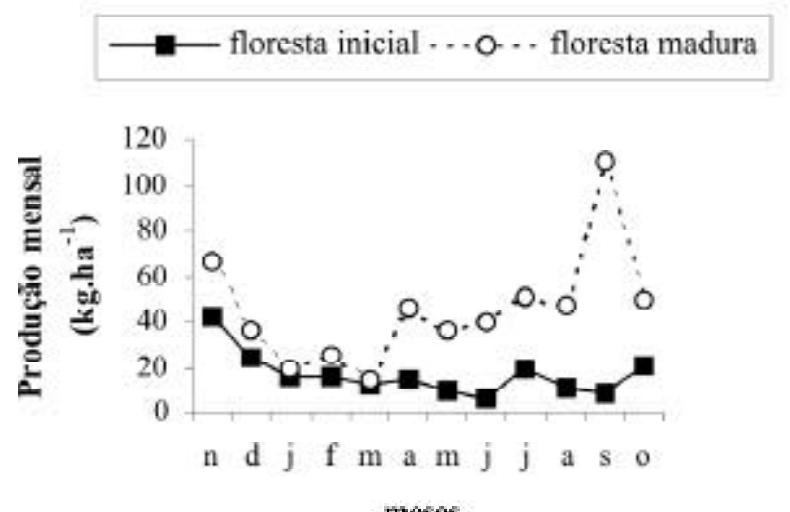

meses

\section{Fração Ramos}
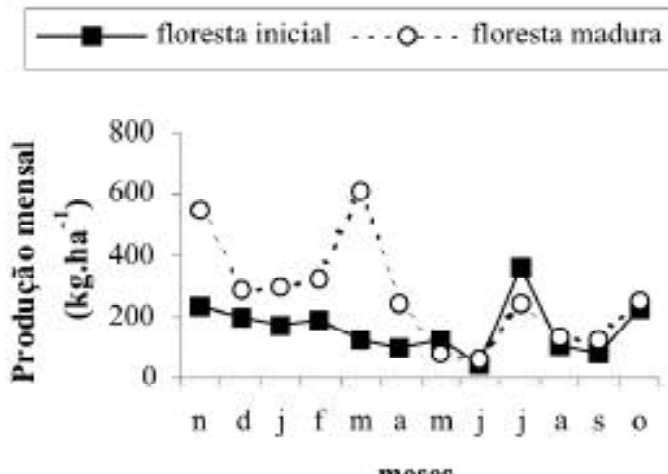

Fração Flores

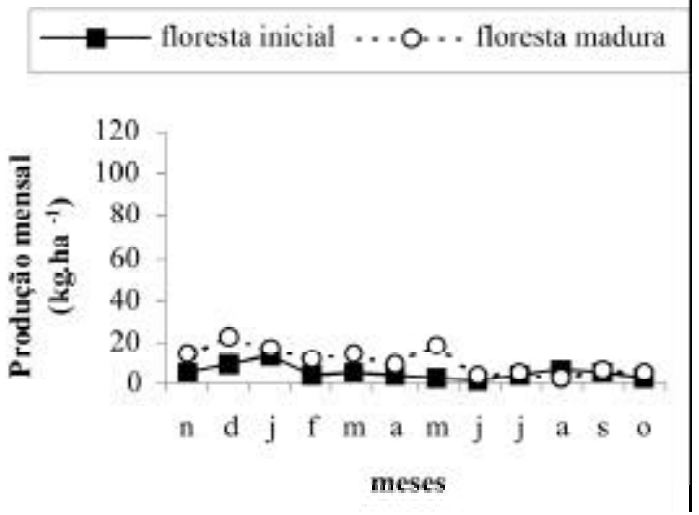

Figura 1 - Produção mensal de serapilheira e das frações folhas, ramos, frutos/sementes e flores nas florestas inicial e madura na Reserva Mata do Paraíso, em Viçosa, MG.

Figure 1 -Monthly production of total litter and leaves, branches, fruits and seeds and flowers fractions for initial and mature forests in Mata do Paraíso Forest Reserve in Viçosa, MG. 
Apesar de ter sido a fração predominante, o porcentual de contribuição da fração foliar na serapilheira total foi reduzido, se comparado com outros estudos em florestas semidecíduas: 64,5\% (CESAR, 1993), 75,8\% (MARTINS e RODRIGUES, 1999) e 71,5\% (OLIVEIRA, 1997). No entanto, a fração foliar, por ser quantitativamente o componente principal da serapilheira, apresentou ao longo do ano comportamento bastante semelhante ao da produção total de serapilheira.

Os picos de produção da serapilheira total foram registrados em outubro na floresta inicial (782,9 kg.ha $\left.{ }^{1}\right)$ e em novembro na floresta madura (1.076,1 kg.ha), enquanto as maiores deposições da fração foliar foram obtidas em setembro, nos dois trechos de floresta estudados. No entanto, os menores valores de produção de serapilheira total e das frações folhas e ramos foram registrados na transição das estações outono-inverno, durante a estação seca, apresentando o mês de junho as menores produções, tanto na floresta inicial quanto na floresta madura (Figura 1).

A maior deposição da fração foliar no final da estação seca pode ser uma resposta da vegetação ao estresse hídrico, já que a derrubada de folhas reduziria a perda de água por transpiração (MARTINS e RODRIGUES, 1999). No entanto, a ocorrência de ventos fortes em setembro e outubro deve ter atuado como fator mecânico, causando também maior deposição de folhas. A concentração da queda de folhas na estação mais seca do ano e período transicional, constatada numa floresta semidecídua em Campinas, SP, foi atribuída a uma estreita relação entre deciduosidade e estacionalidade climática (MORELLATO, 1995).

A maior queda de folhas no final da estação seca e no início da estação chuvosa, verificada em florestas semidecíduas, tem sido atribuída a vários fatores como disponibilidade de água (CESAR, 1993; POGGIANI e MONTEIROJÚNIOR, 1990), baixatemperatura(POGGIANI e MONTEIRO JÚNIOR, 1990) e disponibilidade de nutrientes (MORELLATO, 1992). Burghouts et al. (1994) indicaram a umidade do solo como o principal fator determinante do padrão de deposição foliar verificado em uma floresta da Malásia.

A fração ramos não apresentou padrão de variação temporal semelhante ao da serapilheira total, coincidindo somente com os menores registros de produção durante o mês de junho nas florestas inicial e madura. As maiores deposições dessa fração ocorreram nos meses de julho na floresta inicial e março na floresta madura (Figura 1). Embora essa fração contribua significativamente para a produção da serapilheira total, ela não apresentou uniformidade em sua produção no decorrer deste estudo. A contribuição dessa fração na biomassa total depositada tem sido muito variada em diversos estudos: $32,6 \%$ (PAGANO, 1989), 27,8\% (CESAR, 1993) e 19,2\% (MARTINS e RODRIGUES, 1999).

A deposição de ramos ocorre em resposta a eventos bióticos e abióticos anteriores à sua deposição. Os eventos bióticos, geralmente, levam a respostas postergadas por um período maior de tempo, enquanto os eventos abióticos geram respostas imediatas à causa, como danos físicos causados por quedas de árvores, ação das chuvas, queda de raios e ventos fortes. Portanto, o padrão de deposição dos ramos é marcado pela heterogeneidade temporal com baixa correlação com as variáveis climáticas, como observado também por König et al. (2002).

A fração frutos e sementes alcançou a máxima produção em novembro na floresta inicial e em setembro na floresta madura, enquanto a menor produção foi registrada nos meses de junho e março nas florestas inicial e madura, respectivamente, apresentando, no entanto, deposição mais homogênea durante o ano na floresta inicial (Figura 1). Morellato et al. (1989) e Pagano (1989) justificam esses picos pela ocorrência, nessa época, de maior quantidade de frutos carnosos. Rodrigues (1992) atribuiu a maior produção de frutos em uma Floresta Estacional Semidecidual no interior de São Paulo à maior participação, durante a primavera, de espécies com frutos secos adaptados à dispersão autocórica ou anemocórica.

Com menor participação na produção total de serapilheira e padrão de deposição bastante irregular durante o ano, a fração flores apresentou picos de produção em janeiro na floresta inicial e dezembro na floresta madura, e as menores deposições em junho na floresta inicial e em agosto na floresta madura (Figura 1). A variação temporal da produção de flores esteve atrelada ao período chuvoso na região, apresentando tendência à maior produção durante o período úmido e a menores durante o período seco, independentemente do trecho de floresta. Portanto, a variação temporal da produção de material reprodutivo (flores, frutos e sementes) está mais relacionada à diversidade de espécies presentes na área de estudo e à fenologia dessas espécies do que ao estádio 
sucessional atual dos trechos de floresta estudados. Assim, os valores de produção desse material num mesmo tipo de floresta podem variar de acordo com a área estudada, pois estão na dependência das condições abióticas locais, da composição florística e da demografia de cada espécie (DINIZ e PAGANO, 1997).

\subsection{Relações entre as variáveis climáticas e a produção de serapilheira}

Na floresta inicial, a produção de serapilheira total apresentou relação positiva significativa $(\mathrm{p}<0,05)$ com a velocidade do vento $(0,66)$ e negativa com a umidade relativa $(-0,60)$, padrão semelhante ao apresentado pela fração folhas (Figura 2). Portanto, as maiores deposições de serapilheira e folhas na floresta inicial ocorreram na época do ano, com incidência de baixa umidade relativa e ventos fortes.

$\mathrm{Na}$ floresta madura as relações significativas ( $\mathrm{p}$ $<0,05)$ e positivas foram obtidas entre a produção de serapilheira total, a temperatura média mensal $(0,65)$, a média mensal das temperaturas máximas $(0,79)$ e a velocidade do vento $(0,74)$. Apenas na umidade relativa houve relação negativa $(-0,78)$, padrão semelhante também na fração foliar (Figura 3). Portanto, as maiores deposições de serapilheira e folhas na floresta madura ocorreram na época do ano com maiores temperaturas, ventos fortes e menor umidade relativa.

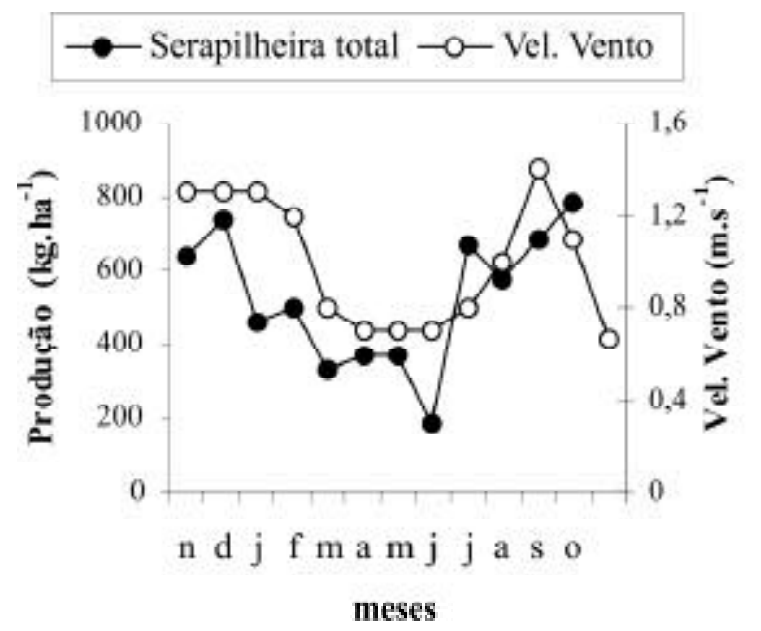

Vários trabalhos têm apresentado padrões bastante variáveis quanto à correlação das variáveis climáticas e à produção de serapilheira. Martins e Rodrigues (1999) observaram correlação significativa positiva para velocidade do vento e negativa para umidade relativa em clareiras de Floresta Estacional Semidecidual. König et al. (2002) apenas encontraram correlação significativa negativa na temperatura média mensal em Floresta Estacional Decidual. Arato et al. (2003), entretanto, não observaram correlações significativas entre a produção de serapilheira e a produção desta em um sistema agroflorestal.

\subsection{Correlação entre a estrutura da vegetação e a produção de serapilheira}

No Quadro 3 são apresentadas as características estruturais da vegetação arbustivo arbórea amostrada nas parcelas da floresta inicial e floresta madura e a produção de serapilheira total nessas parcelas. De posse dessas características, foram feitos ajustes de regressões para verificar a relação entre a produção de serapilheira e a estrutura dos dois trechos de floresta estudados. Como não foram significativos os ajustes independentes de cada trecho de floresta, utilizaram-se todas as parcelas amostradas, permitindo um ajuste de regressão da área estudada como um todo, ou seja, os dois estádios sucessionais.

Figura 2 - Produção mensal da serapilheira total em relação à velocidade do vento e umidade relativa na floresta inicial na Reserva Mata do Paraíso, em Viçosa, MG.

Figure 2-Monthly production of total litter in relation to the speed of the wind and relative humidity for initial and mature forests in Mata do Paraíso Forest Reserve in Viçosa, $M G$.

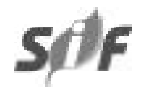

R. Árvore, Viçosa-MG, v.32, n.3, p.545-556, 2008 

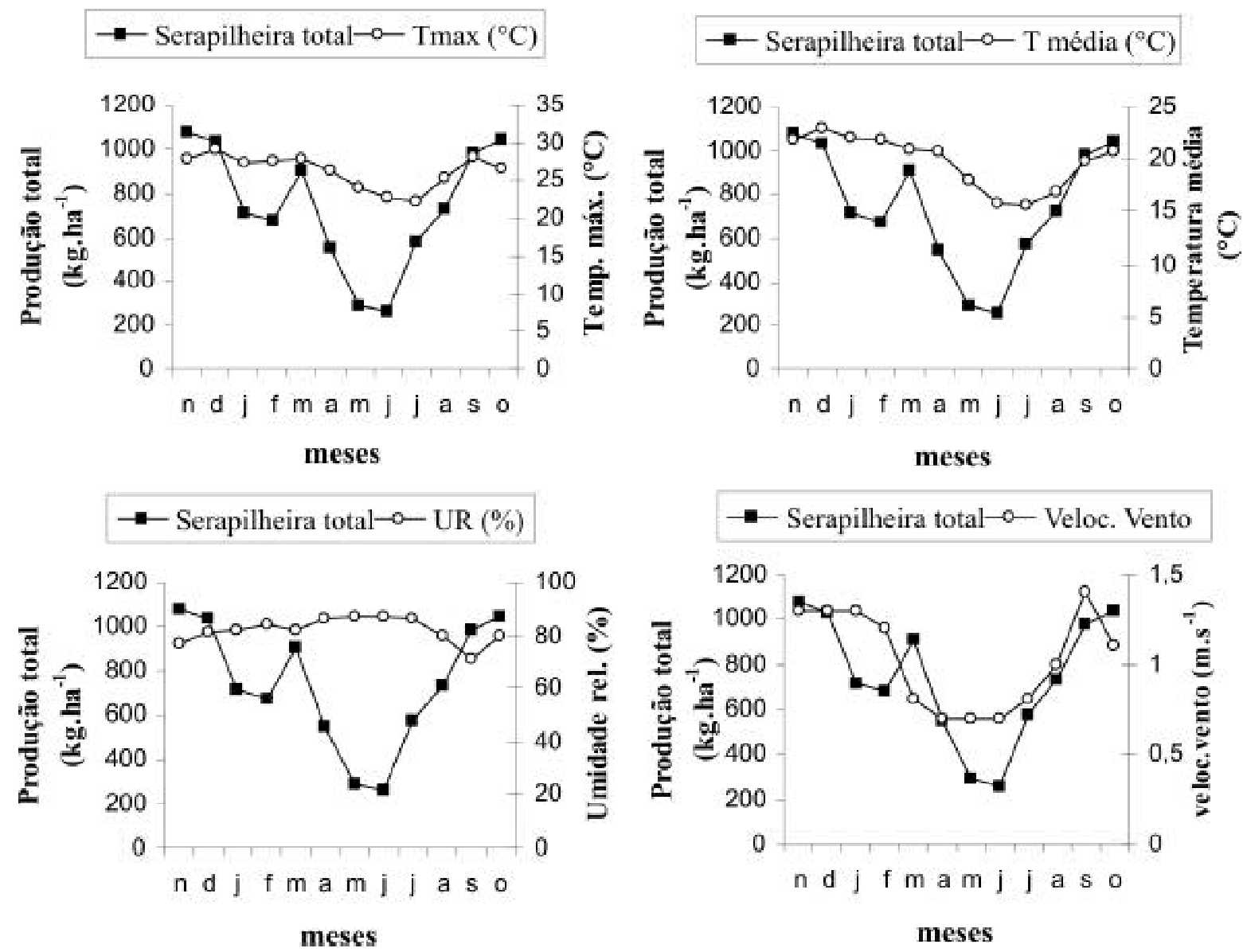

Figura 3 - Produção mensal da serapilheira total em relação à média mensal das temperaturas máximas, temperatura média mensal, umidade relativa e velocidade do vento na floresta madura na Reserva Mata do Paraíso, em Viçosa, MG.

Figure 3 - Monthly production of total litter in relation to the monthly average of the maximum temperatures, monthly medium temperature, relative humidity and speed of the wind for initial and mature forests in Mata do Paraiso Forest Reserve in Viçosa, $M G$.

No conjunto das parcelas, as análises de regressão indicaram que a produção de serapilheira total por parcela não apresentou correlação significativa com o número de indivíduos amostrados na categoria sucessional pioneiras $(\mathrm{P}=0,206)$, com a altura média das árvores em cada parcela $(\mathrm{P}=0,195)$ e com a porcentagem de abertura do dossel $(\mathrm{P}=0,126)$. No entanto, a produção de serapilheira apresentou relação significativa com a densidade $(\mathrm{P}=$ 0,$\left.001 ; \mathrm{R}^{2}=0,66\right)$ e com a área basal $\left(\mathrm{P}=0,005 ; \mathrm{R}^{2}=0,60\right)$ dos indivíduos arbóreo-arbustivos de cada parcela (Figura 4). Portanto, as parcelas com maior número de indivíduos e indivíduos com diâmetros maiores apresentaram tendência à maior produção de serapilheira.

R. Árvore, Viçosa-MG, v.32, n.3, p.545-556, 2008
A relação significativa encontrada entre a produção de serapilheira e a densidade (número indivíduos por $\mathrm{m}^{2}$ ) e a área basal nas parcelas demonstraram que a produção de serapilheira aumentou com a densidade e a biomassa presente no ambiente. Portanto, a estrutura vertical e horizontal da floresta, representadas, principalmente, pelo porte da vegetação, estão, nesse caso, associadas à maior produção de serapilheira. Essa relação explica a maior produção de serapilheira na floresta madura, que apresentou maior densidade de indivíduos arbóreos e maior área basal em comparação com a floresta inicial.

R. Árvore, Viçosa-MG, v.32, n.3, p.545-556, 2008 
Quadro 3 - Parcelas amostradas nas florestas inicial e madura na Reserva Mata do Paraíso, em Viçosa, MG, com os respectivos valores de produção de serapilheira, densidade, número de indivíduos amostrados da categoria sucessional pioneiras, área basal, altura média e porcentagem de abertura do dossel

Table 3 - Plots sampled in the initial and mature forests in the Mata do Paraiso Forest Reserve in Viçosa, MG, with respective values of litter production, density, number of individuals sampled of pioneer successional categories, basal area, average height and canopy openness

\begin{tabular}{|c|c|c|c|c|c|c|c|}
\hline Trecho Estudado & Parcela & $\begin{array}{c}\text { Produção } \\
\text { Total }\end{array}$ & Densidade & $\begin{array}{l}\text { Número } \\
\text { Pioneiras }\end{array}$ & Área Basal & Altura Média & Abertura Dossel \\
\hline & & $\mathrm{kg} \cdot \mathrm{ha}^{-1}$ & Ind. $\mathrm{m}^{-2}$ & & $\mathrm{~m}^{2}$ & $\mathrm{~m}$ & $\%$ \\
\hline \multirow{10}{*}{ Floresta Inicial } & 1 & 640,8 & 0,12 & 9 & 0,4228 & 8,8 & 5,32 \\
\hline & 2 & 595,6 & 0,17 & 29 & 0,6805 & 9,6 & 6,12 \\
\hline & 3 & 677,9 & 0,13 & 24 & 0,6631 & 10,3 & 6,40 \\
\hline & 4 & 511,2 & 0,12 & 18 & 0,6050 & 10,8 & 7,61 \\
\hline & 5 & 644,0 & 0,14 & 24 & 0,6325 & 9,9 & 7,25 \\
\hline & 6 & 708,9 & 0,13 & 17 & 0,7639 & 9,9 & 2,74 \\
\hline & 7 & 812,59 & 0,11 & 11 & 0,3151 & 7,8 & 3,44 \\
\hline & 8 & 750,1 & 0,16 & 19 & 0,4753 & 8,2 & 7,76 \\
\hline & 9 & 662,0 & 0,16 & 21 & 0,4964 & 8,8 & 6,17 \\
\hline & 10 & 307,4 & 0,09 & 3 & 0,4642 & 7,7 & 5,65 \\
\hline \multirow{10}{*}{ Floresta Madura } & 11 & 436,0 & 0,16 & 0 & 0,6228 & 9,0 & 4,32 \\
\hline & 12 & 766,0 & 0,21 & 6 & 0,8181 & 9,1 & 3,24 \\
\hline & 13 & 989,0 & 0,17 & 5 & 1,1403 & 10,1 & 4,03 \\
\hline & 14 & $1.137,2$ & 0,19 & 6 & 0,9853 & 9,9 & 4,38 \\
\hline & 15 & 895,3 & 0,26 & 3 & 1,6913 & 10,7 & 3,32 \\
\hline & 16 & $1.183,7$ & 0,25 & 5 & 1,2291 & 9,9 & 5,97 \\
\hline & 17 & $1.017,9$ & 0,22 & 2 & 1,3121 & 9,0 & 2,88 \\
\hline & 18 & 824,1 & 0,17 & 2 & 1,3310 & 10,8 & 2,93 \\
\hline & 19 & 714,4 & 0,22 & 0 & 1,3723 & 10,1 & 3,37 \\
\hline & 20 & 856,1 & 0,22 & 1 & 0,9552 & 10,1 & 2,51 \\
\hline
\end{tabular}
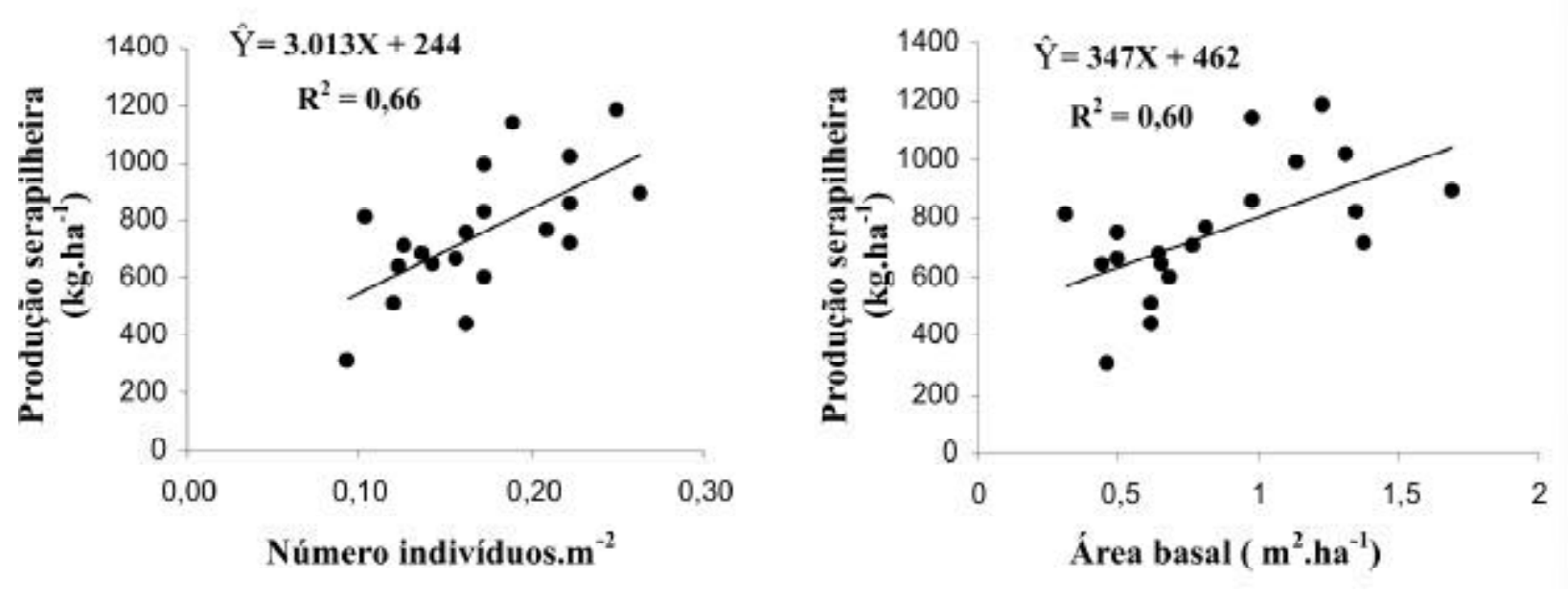

Figura 4 - Produção anual de serapilheira em função da densidade (número de indivíduos por m2) e da área basal nos dois trechos de floresta estudados na Reserva Mata do Paraíso, em Viçosa, MG.

Figure 4 - Annual production of litter in function of the density (number of individuals for $m 2$ ) and of the basal area for initial and mature forests in the Mata do Paraiso Forest Reserve in Viçosa, MG.

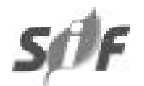

R. Árvore, Viçosa-MG, v.32, n.3, p.545-556, 2008 
Em área de floresta atlântica e de floresta de restinga na Ilha do Cardoso, SP, foi verificada menor produção de serapilheira na floresta de restinga, onde o volume de biomassa era inferior, como reflexo da menor abundância de indivíduos por hectare e um dossel mais baixo (MORAES et al., 1999). Werneck et al. (2001), estudando a produção de serapilheira na Floresta Semidecidual da Estação Ecológica de Tripuí, em Ouro Preto (MG), observaram que a maior produção de serapilheira não estava condicionada à presença de grande número de espécies pioneiras, que são encontradas em abundância nos trechos mais perturbados e em estádio inicial de sucessão. A produção de serrapileira relacionava-se mais à estrutura da floresta e à conseqüente formação de um dossel mais desenvolvido. Portanto, a abundância de espécies pioneiras nas florestas em estádio inicial de sucessão pode ser menos importante que a densidade de indivíduos e o porte das árvores que compõem o dossel na determinação da produção de serapilheira (SONGWE et al., 1988).

\section{CONCLUSÕES}

A deposição de serapilheira total mostrou-se sazonal, com as maiores produções ocorrendo no início da primavera, nos dois estádios sucessionais estudados. A produção de serapilheira na floresta madura foi superior à da floresta inicial, sendo a fração foliar a mais sazonal entre as frações estudadas e com padrão de variação temporal semelhante ao da serapilheira total.

A influência das variáveis climáticas na variação temporal de produção de serapilheira foi constatada pela relação entre a produção de serapilheira e a velocidade do vento, temperatura e umidade relativa nos dois trechos de floresta estudados.

A produção de serapilheira total relacionou-se positivamente com a área basal e a densidade dos indivíduos nas parcelas, demonstrando a correlação entre a produção de serapilheira e as estruturas horizontal e vertical dos trechos de floresta estudados.

\section{AGRADECIMENTOS}

Ao Conselho Nacional de Desenvolvimento Científico e Tecnológico-CNPq, pelas bolsas de mestrado de Sheila I. C. Pinto e de Produtividade em Pesquisa de Sebastião V. Martins e Nairam F. Barros; e aos estagiários do Curso de Engenharia Florestal da UFV
Carlos José A. Silveira e Leonardo M. P. dos Santos, pelo auxílio nos trabalhos de campo.

\section{REFERÊNCIAS}

ARATO, H.D.; MARTINS, S.V.; FERRARI, S.H. Produção e decomposição de serapilheira em um sistema agroflorestal implantado para recuperação de áreas degradadas em Viçosa-MG. Revista Árvore, v. 27, p. 715-721, 2003.

BRAZ, D.M.; CARVALHO OKANO, R.M.; KAMEYAMA, C. Acanthaceae da Reserva Florestal Mata do Paraíso, Viçosa, Minas Gerais. Revista Brasileira de Botânica, v.25, p.495-504, 2002.

BURGHOUTS, T.B.A.; CAMPBELL, E.J.F.; KOLDERMAN, P.J. Effects of tree species heterogeneity on leaf fall in primary and logged dipterocarp forest in the Ulu Segama Forest Reserve, Sabah, Malaysia. Journal of Tropical Ecology, v.10, p.1-26, 1994.

CASTRO, P.S.; VALENTE, O.F.; COELHO, D.T.; RAMALHO, R.S. Interceptação da chuva por mata natural secundária na região de Viçosa, MG. Revista Árvore, v.7, p.76-89, 1983.

CESAR, O. Produção de serapilheira na mata mesófila semidecídua da Fazenda Barreiro Rico, município de Anhembi, SP. Revista Brasileira de Biologia, v. 53, p. 671-681, 1993.

DANTAS, M.; PHILLIPSON, J. Litterfall and litter nutrient content in primary and secondary Amazonian "terra firme" rain forest. Journal of Tropical Ecology, v. 5, p. 27-36, 1989.

DIAS, H.C.T.; OLIVEIRA FILHO, A.T. Variação temporal e espacial da produção de serapilheira em uma área de floresta estacional semidecídua montana em Lavras-MG. Revista Árvore, v.21, p.11-26, 1997.

DINIZ, S.; PAGANO, S.N. Dinâmica de folhedo em floresta mesófila semidecídua no município de Araras, SP. Revista do Instituto Florestal, v.9, p.27-36, 1997.

FACELLI, J.M.; PICKETT, S.T.A. Plant litter: its dynamics and effects on plant community structure. The Botanical Review, v.57, p.1-32, 1991. 
FIGUEIREDO FILHO, A.; MORAES, G.F.; SCHAAF, L.B.; FIGUEIREDO, D.J. Avaliação estacional da deposição de serapilheira em uma floresta ombrófila mista localizada no sul do Estado do Paraná.

Ciência Florestal, v.13, p.11-18, 2003.

GANDOLFI, S.; LEITÃOFILHO, H.F.; BEZERRA, C.L.F. Levantamento florístico e caráter das espécies arbustivo-arbóreas de uma floresta mesófila semidecídua no município de Guarulhos, SP.Revista Brasileira de Biologia, v.55, n.4, p.753-767, 1995.

LEITÃO-FILHO, H.F.; PAGANO, S.N.; CESAR, O.; TIMONI, J.L.; RUEDA, J.J. Ecologia da Mata Atlântica em Cubatão. Editora da UNESP. São Paulo - Editora da UNICAMP. Campinas. 1993.

LOWMAN, M.D. Litterfall and leaf decay in three Australian rainforest formations. Journal of Ecology, v.76, p.451-465, 1988.

KÖNIG, F.G.; SCHUMACHER, M.V.; BRUN, E.J.; SCLING, I. Avaliação da sazonalidade da produção de serapilheira numa floresta estacional decidual no município de Santa Maria, RS. Revista Árvore, v.26, n.4, p.429-435, 2002.

MARTINS, S.V.; RODRIGUES, R.R. Produção de serapilheira em clareiras de uma floresta estacional semidecidual no município de Campinas, SP. Revista Brasileira de Botânica, v.22, p.405-412, 1999.

MARTIUS, C.; HÖFER, H.; GARCIA, M.V.B.; RÖMBKE, J.; HANAGARTH, W. Litter fall, litter stocks and decomposition rates in rainforest and agroforestry sites in central Amazônia. Nutrient Cycling in Agroecosystems, v.68, p.137-154, 2004.

McDONALD, M.A.; HEALY, J.R. Nutrient cycling in secondary forests in the Blue Mountains of Jamaica. Forest Ecology and

Management, v.139, p.257-278, 2000.

MOLOFSKY, J.; AUGSPURGER, C.K. The effect of litter on early seedling establishment in a tropical forest. Ecology, v. 73, p. 68-77, 1992.

MORAES, R.M.; DELITTI, W.B.C.; VUONO, Y.S. Litterfall and litter nutrient content in two Brazilian Tropical Forests. Revista Brasileira de Botânica, v. 22, p. 9-16, 1999.
MORELLATO, L.P.C.; RODRIGUES, R.R.; LEITÃOFILHO, H.F.; JOLY, C.A. Estudo fenológico comparativo de espécies arbóreas de floresta de altitude e floresta mesófila semidecídua na Serra do Japí, Jundiaí, SP. Revista Brasileira de Botânica, v. 12, p. 85-98, 1989.

MORELLATO, L.P.C. As estações do ano na floresta. In: MORELLATO, L.P.C.; LEITÃO FILHO, H.F. (Eds.). Ecologia e preservação de uma floresta tropical urbana: Reserva de Santa Genebra. Campinas: Editora da UNICAMP, p.37-41, 1995.

MORELLATO, L.P.C. Nutrient cycling in two south-east Brazilian forests. I Litterfall and litter standing crop. Journal of Tropical Ecology, v. 8, p. 205-215, 1992.

OLIVEIRA, R.E. Aspectos da dinâmica de um fragmento florestal em Piracicaba-SP: silvigênese e ciclagem de nutrientes. 1997. 79f. Dissertação (Mestrado em recursos Florestais) - Escola Superior de Agricultura “Luiz de Queiroz”, Piracicaba, 1997.

OLIVEIRA JÚNIOR, J.C.; DIAS, H.C.T. Precipitação efetiva em fragmento secundário da Mata Atlântica. Revista Árvore, v.29, p. 9-15, 2005.

PAGANO, S.N. Produção de folhedo em mata mesófila semidecídua no município de Rio Claro, SP. Revista Brasileira de Biologia, v. 49, p.633-639, 1989.

POGGIANI, F.; MONTEIRO JÚNIOR, E.S. Deposição de folhedo e retorno de nutrientes ao solo numa floresta estacional semidecídua, em Piracicaba (Estado de SP). In: VI CONGRESSO FLORESTAL BRASILEIRO, 1990, Campos do Jordão. Anais ... Campos do Jordão: SBS/SBEF, 1990. p.596-602.

PROCTOR, J. 1983. Tropical forest litterfall I Problems of data comparison. In: SUTTON, S.L.; WHITMORE, T.C.; CHADWICK, A.C. (Eds.)

Tropical Rain Forest: ecology and Management. London: Blacekwell Scientific Publications, p. 267-273, 1983.

R. Árvore, Viçosa-MG, v.32, n.3, p.545-556, 2008 
RODRIGUES, M.G. Sazonalidade na dieta de vertebrados frugívoros em uma floresta semidecídua no Brasil. 1992. Dissertação (Mestrado). Universidade Estadual de Campinas, Campinas, 1992.

SANCHEZ, G.R.; ALVAREZ SANCHEZ, J. Litterfall in primary and secondary tropical forests of Mexico. Tropical Ecology, v. 36, p. 191-201, 1995.

SILVA JÚNIOR, W.M.; MARTINS, S.V.; SILVA, A.F.; DE MARCO JÚNIOR, P. Regeneração natural de espécies arbustivo-arbóreas em dois trechos de uma floresta estacional semidecidual, Viçosa, MG.

Scientia Forestalis, v. 66, p. 169-179, 2004.
SONGWE, N.C.; FASEHUN, F.E.; OKALI, D.U.U. Litterfall and productivity in a tropical rain forest, Southern Bankundu Forest, Camerron. Journal of Tropical Ecology, v. 4, p. 25-37, 1988.

STEEGE, H. HEMIPHOT: a program to analyze vegetation indice, light and light quality from hemispherical photographs . Wageningen: The Tropenbos Foundation. 1993.

WERNECK, M.S.; PEDRALLI, G.; GIESEKE, L.F. Produção de serapilheira em trechos de uma floresta semidecídua com diferentes graus de perturbação na Estação Ecológica do Tripuí, Ouro Preto, MG. Revista Brasileira de Botânica, v. 24, p. 195-198, 2001. 